\title{
Message From the PRESIDENT OF THE SOUTH AFRICAN SOCIETY OF PHYSIOTHERAPY
}

$\mathrm{T}$ The 75th anniversary of the South African Society of Physiotherapy is an achievement that the profession can be proud of and gives opportunity to acknowledge the successes of the past. However it is not a time for complacency and the SASP must continue to move forward. This is not always easy - Niccolo Machiavelli said "There is nothing more difficult to take in hand, more perilous to conduct, or more uncertain in its success, than to take the lead in the introduction of a new order of things"

Several years ago the SASP embarked on a restructuring process. One of the prime objectives was to de-centralise the activities to the provinces and in many instances this has been extremely successful. The introduction of an executive director was not such a successful venture, but as should happen, lessons were learnt and other strengths realised.

Time has passed and changes in health policy, both within the private and public sector have resulted in new roles for the SASP. Negotiation, lobbying, education, quality assurance to name but a few. Alongside this, has been the realisation that the organization and substructures cannot work in isolation, nor can they rely on volunteers (however committed to maintain the process).

It is in this light that we see the next phase of development of the SASP. A very exciting one, integrating all our resources and activities which will result in a stronger more effective and efficient professional body. This will require a paradigm shift in thinking for some, who have compartmentalised activities, but the sharing of expertise can only be beneficial.

A new vision for the SASP is part of the process. I share it with you and comments are welcome.

\section{SOLITH AFRICAN SOCIETY OF PHYSIOTHERAPY Vision:}

- The South African Society of Physiotherapy is the representative body for the physiotherapy profession in South Africa. It is dynamic, professional and innovative, having credibility amongst its members, health care professionals, policy makers and the public.

- It is a united body representing all facets of the profession, and membership, both clinically and demographically. It will be proactive and politically influential acting as an advocate for the profession in all aspects.

- The SASP will further develop and maintain the ethical and clinical standards of the profession, appropriate to South Africa, whilst promoting accessible, affordable and appropriate health care for all.
- It will act as a resource base for physiotherapists, health care providers and policy makers, both at national and international level. Through its efforts, supported by research, physiotherapists will be seen as leaders in the field of rehabilitation and active participants in education, health promotion and prevention of disease and disability, striving for excellence at all times.

Michael Karni said - "The very best way to predict the future is to create it"

The current management structures are endeavouring to create what we see as an appropriate organization, in response to the changing needs.

I hope that future generations of physiotherapists will look back and acknowledge our achievements. Until then, lets all look towards the future with excitement and commitment.

\section{ANNA BIZOS}

\section{YEARS OF SASP}

$\mathrm{O}_{\mathrm{s}}^{\mathrm{n}}$ behalf of all member countries of the Africa region of the World Confederation for Physical Therapy (WCPT-Africa), I write to congratulate the South Africa Society of Physiotherapy (SASP) on its 75th anniversary. Indeed, the SASP has grown from the period of international isolation to a period when it joins other countries in developing the physiotherapy profession on the Africa continent. This is very evident in the services provided by the official journal of the association - The South African Journal of Physiotherapy.

The journal has moved away from an introspective South African journal to an out-looking African journal, which receives manuscripts from different countries in Africa. The editorial board is known to have freely assisted some authors in improving their writing skills before the manuscripts are accepted for publication. At the moment, the South African Journal of Physiotherapy is the only accredited physiotherapy journal published on the continent. As the chairperson of WCPT-Africa, I can categorically state that these services are of great value for the professional growth of physiotherapists on the continent.

CONGRATULATIONS!

PROF DELE AMOSUN Chairperson, WCPT-Africa 